\title{
The Analytical Solution of Some Fractional Ordinary Differential Equations by the Sumudu Transform Method
}

\author{
Hasan Bulut, ${ }^{1}$ Haci Mehmet Baskonus, ${ }^{2}$ and Fethi Bin Muhammad Belgacem ${ }^{3}$ \\ ${ }^{1}$ Department of Mathematics, Firat University, Elazig, Turkey \\ ${ }^{2}$ Department of Computer Engineering, Tunceli University, Tunceli, Turkey \\ ${ }^{3}$ Department of Mathematics, Faculty of Basic Education, PAAET, Shamiya, Kuwait
}

Correspondence should be addressed to Hasan Bulut; hbulut@firat.edu.tr

Received 16 March 2013; Accepted 31 July 2013

Academic Editor: Santanu Saha Ray

Copyright (C) 2013 Hasan Bulut et al. This is an open access article distributed under the Creative Commons Attribution License, which permits unrestricted use, distribution, and reproduction in any medium, provided the original work is properly cited.

\begin{abstract}
We introduce the rudiments of fractional calculus and the consequent applications of the Sumudu transform on fractional derivatives. Once this connection is firmly established in the general setting, we turn to the application of the Sumudu transform method (STM) to some interesting nonhomogeneous fractional ordinary differential equations (FODEs). Finally, we use the solutions to form two-dimensional (2D) graphs, by using the symbolic algebra package Mathematica Program 7.
\end{abstract}

\section{Introduction}

The Sumudu transform was first defined in its current shape by Watugala as early as 1993, which he used to solve engineering control problems. Although he might have had ideas for it sooner than that (1989) as some conference proceedings showed, he used it to control engineering problems $[1,2]$. Later, Watugala extended in 2002 the Sumudu transform to two variables [3]. The first applications to differential equations and inversion formulae were done by Weerakoon in two papers in 1994 and 1998 [4, 5]. The Sumudu transform was also first defended by Weerakoon against Deakin's definition who claimed that there is no difference between the Sumudu and the Laplace and who reminded Weerakoon that the Sumudu transform is really the Carson or the S-multiplied transform disguised $[6,7]$. The applications followed in three consecutive papers by Asiru dealing with the convolution-type integral equations and the discrete dynamic systems $[8,9]$. At this point, Belgacem et al. using previous references and connections to the Laplace transform extended the theory and the applications of the Sumudu transform in [10-17] to various applications. In the meantime, subsequent to exchanges between Belgacem and other scholars, the following papers sprang up in the last decade [18-22]. Moreover, the Sumudu transform was also used to solve many ordinary differential equations with integer order [23-29]. The application of STM turns out to be pragmatic in getting analytical solution of the fractional ordinary differential equations fast. Notably, implementations of difference methods such as in the differential transform method (DTM), the Adomian decomposition method $(\mathrm{ADM})$ [30-33], the variational iteration method (VIM) [34-40] empowered us to achieve approximate solutions of various ordinary differential equations. STM [41-44] which is newly submitted to the literature is a suitable technique for solving various kinds of ordinary differential equations with fractional order (FODEs). In this sense, it is estimated that this novel approach that is used to solve homogeneous and nonhomogeneous problems will be particularly valuable as a tool for scientists and applied mathematicians.

\section{Fundamental Properties of Fractional Calculus and STM}

2.1. Fundamental Facts of the Fractional Calculus. Firstly, we mention some of the fundamental properties of the fractional calculus. Fractional derivatives (and integrals as well) definitions may differ, but the most widely used definitions are those of Abel-Riemann (A-R). Following the nomenclature 
in [45], a derivative of fractional order in the A-R sense is defined by

$$
\begin{aligned}
& D^{\alpha}[f(t)] \\
& = \begin{cases}\frac{1}{\Gamma[m-\alpha]} \frac{d}{d t^{m}} \int_{0}^{t} \frac{f(\tau)}{(t-\tau)^{\alpha-m+1}} d \tau, & m-1<\alpha \leq m, \\
\frac{d^{m}}{d t^{m}} f(t), & \alpha=m,\end{cases}
\end{aligned}
$$

where $m \in \mathbb{Z}^{+}$and $\alpha \in R^{+} . D^{\alpha}$ is a derivative operator here, and

$$
D^{-\alpha}[f(t)]=\frac{1}{\Gamma[\alpha]} \int_{0}^{t}(t-\tau)^{\alpha-1} f(\tau) d \tau, \quad 0<\alpha \leq 1
$$

On the other hand, according to A-R, an integral of fractional order is defined by implementing the integration operator $J^{\alpha}$ in the following manner:

$$
J^{\alpha}[f(t)]=\frac{1}{\Gamma[\alpha]} \int_{0}^{t}(t-\tau)^{\alpha-1} f(\tau) d \tau, \quad t>0, \alpha>0 .
$$

When it comes to some of the fundamental properties of fractional integration and fractional differentiation, these have been introduced to the literature by Podlubny [46]. Among these, we mention

$$
\begin{aligned}
J^{\alpha}\left[t^{n}\right] & =\frac{\Gamma[1+n]}{\Gamma[1+n+\alpha]} t^{n+\alpha}, \\
D^{\alpha}\left[t^{n}\right] & =\frac{\Gamma[1+n]}{\Gamma[1+n-\alpha]} t^{n-\alpha} .
\end{aligned}
$$

Another main definition of the fractional derivative is that of Caputo $[46,47]$ who defined it by

$$
\begin{aligned}
{ }^{C} D^{\alpha} & {[f(t)] } \\
& = \begin{cases}\frac{1}{\Gamma[m-\alpha]} \int_{0}^{t} \frac{f^{(m)}(\tau)}{(t-\tau)^{\alpha-m+1}} d \tau, & m-1<\alpha<m, \\
\frac{d^{m}}{d t^{m}} f(t), & \alpha=m .\end{cases}
\end{aligned}
$$

A fundamental feature of the Caputo fractional derivative is that [17]

$$
J^{\alpha}\left[{ }^{C} D^{\alpha} f(t)\right]=f(t)-\sum_{k=0}^{\infty} f^{(k)}\left(0^{+}\right) \frac{t^{k}}{k !} .
$$

2.2. Fundamental Facts of the Sumudu Transform Method. The Sumudu transform is defined in $[1,2]$ as follows. Over the set of functions

$$
\begin{aligned}
A=\left\{f(t) \mid \exists M, \tau_{1}, \tau_{2}>0,\right. & \\
& \left.|f(t)|<M e^{|t| / \tau_{i}}, \text { if } t \in(-1)^{j} \times[0, \infty)\right\},
\end{aligned}
$$

the Sumudu transform of $f(t)$ is defined as

$$
F(u)=S[f(t)]=\int_{0}^{\infty} f(u t) e^{-t} d t, \quad u \in\left(-\tau_{1}, \tau_{2}\right) .
$$

Theorem 1. If $F(u)$ is the Sumudu transform of $f(t)$, one knows that the Sumudu transform of the derivatives with integer order is given as follows [46-49]:

$$
S\left[\frac{d f(t)}{d t}\right]=\frac{1}{u}[F(u)-f(0)] .
$$

Proof. Let us take the Sumudu transform [46-49] of $f^{\prime}(t)=$ $d f(t) / d t$ as follows:

$$
\begin{aligned}
S\left[\frac{d f(t)}{d t}\right] & =\int_{0}^{\infty} \frac{d f(u t)}{d t} e^{-t} d t=\lim _{p \rightarrow \infty} \int_{0}^{p} \frac{d f(u t)}{d t} e^{-t} d t \\
& =\lim _{p \rightarrow \infty}\left[\left.\frac{1}{u} e^{-(t / u)} f(t)\right|_{0} ^{p}+\frac{1}{u^{2}} \int_{0}^{p} e^{-(t / u)} f(t) d t\right] \\
& =\lim _{p \rightarrow \infty}\left[\left.\frac{1}{u} e^{-(t / u)} f(t)\right|_{0} ^{p}\right. \\
& =\lim _{p \rightarrow \infty}\left[-\frac{1}{u}\left(\frac{1}{u} \int_{0}^{p} e^{-(t / u)} f(t) d t\right)\right] \\
& =-\frac{1}{u} f(0)+\frac{1}{u} F(u) .
\end{aligned}
$$

Equation (10) gives us the proof of Theorem 1. When we continue in the same manner, we get the Sumudu transform of the second-order derivative as follows [46-49]:

$$
S\left[\frac{d^{2} f(t)}{d t^{2}}\right]=\frac{1}{u^{2}}\left[F(u)-f(0)-\left.u \frac{d f(t)}{d t}\right|_{t=0}\right] .
$$

If we go on the same way, we get the Sumudu transform of the $n$-order derivative as follows:

$$
S\left[\frac{d^{n} f(t)}{d t^{n}}\right]=u^{-n}\left[F(u)-\left.\sum_{k=0}^{n-1} u^{k} \frac{d^{n} f(t)}{d t^{n}}\right|_{t=0}\right] .
$$

Theorem 2. If $F(u)$ is the Sumudu transform of $f(t)$, one can take into consideration the Sumudu transform of the RiemannLiouville fractional derivative as follows [17]:

$$
\begin{array}{r}
S\left[D^{\alpha} f(t)\right]=u^{-\alpha}\left[F(u)-\sum_{k=1}^{n} u^{\alpha-k}\left[D^{\alpha-k}(f(t))\right]_{t=0}\right], \\
-1<n-1 \leq \alpha<n .
\end{array}
$$

Proof. Let us take the Laplace transform of $f^{\prime}(t)=d f(t) / d t$ as follows:

$$
\begin{aligned}
L\left[D^{\alpha} f(t)\right] & =s^{\alpha} F(s)-\sum_{k=0}^{n-1} s^{k}\left[D^{\alpha-k-1}(f(t))\right]_{t=0} \\
& =s^{\alpha} F(s)-\sum_{k=0}^{n} s^{k-1}\left[D^{\alpha-k}(f(t))\right]_{t=0} .
\end{aligned}
$$


Therefore, when we substitute $1 / u$ for $s$, we get the Sumudu transform of fractional order of $f(t)$ as follows:

$$
S\left[D^{\alpha} f(t)\right]=u^{-\alpha}\left[F(u)-\sum_{k=1}^{n} u^{\alpha-k}\left[D^{\alpha-k}(f(t))\right]_{t=0}\right] .
$$

Now, we will introduce the improvement form of STM for solving FODEs. We take into consideration a general linear ordinary differential equation with fractional order as follows:

$$
\frac{\partial^{\alpha} U(t)}{\partial t^{\alpha}}=\frac{\partial^{2} U(t)}{\partial t^{2}}+\frac{\partial U(t)}{\partial t}+U(t)+c,
$$

being subject to the initial condition

$$
U(0)=f(0) \text {. }
$$

Then, we will obtain the analytical solutions of some of the fractional ordinary differential equations by using STM. When we take the Sumudu transform of (16) under the terms of (12) and (15), we obtain the Sumudu transform of (16) as follows:

$$
\begin{aligned}
& S\left[\frac{\partial^{\alpha} U(t)}{\partial t^{\alpha}}\right]=S\left[\frac{\partial^{2} U(t)}{\partial t^{2}}\right]+S\left[\frac{\partial U(t)}{\partial t}\right]+S[U(t)]+S[c], \\
& u^{-\alpha}\left[F(u)-\sum_{k=1}^{n} u^{\alpha-k}\left[D^{\alpha-k}(U(t))\right]_{t=0}\right] \\
& =\frac{1}{u^{2}}\left[F(u)-f(0)-\left.u \frac{\partial f(t)}{\partial t}\right|_{t=0}\right] \\
& +\frac{1}{u}[F(u)-f(0)]+F(u)+c, \\
& F(u)-\sum_{k=1}^{n} u^{\alpha-k}\left[D^{\alpha-k}(U(t))\right]_{t=0} \\
& =u^{\alpha-2}\left[F(u)-f(0)-\left.u \frac{\partial U(t)}{\partial t}\right|_{t=0}\right] \\
& +u^{\alpha-1}[F(u)-f(0)] \\
& +u^{\alpha} F(u)+c u^{\alpha} \text {, } \\
& F(u)=u^{\alpha-2} F(u)-u^{\alpha-2} U(0) \\
& +\sum_{k=1}^{n} u^{\alpha-k}\left[D^{\alpha-k}(U(t))\right]_{t=0}-\left.u^{\alpha-1} \frac{\partial U(t)}{\partial t}\right|_{t=0} \\
& +u^{\alpha-1} F(u)-u^{\alpha-1} f(0) \\
& +u^{\alpha} F(u)+c u^{\alpha} \text {, } \\
& F(u)-u^{\alpha-2} F(u)-u^{\alpha-1} F(u)-u^{\alpha} F(u) \\
& =-u^{\alpha-2} f(0) \\
& +\sum_{k=1}^{n} u^{\alpha-k}\left[D^{\alpha-k}(U(t))\right]_{t=0}-\left.u^{\alpha-1} \frac{\partial U(t)}{\partial t}\right|_{t=0} \\
& -u^{\alpha-1} U(0)+c u^{\alpha} \text {, } \\
& F(u)=\frac{1}{1-u^{\alpha-2}-u^{\alpha-1}-u^{\alpha}} \\
& \times\left[g(u)-u^{\alpha-1} U(0)-u^{\alpha-2} U(0)+c u^{\alpha}\right],
\end{aligned}
$$

where $g(u)$ is defined by $\sum_{k=1}^{n} u^{\alpha-k}\left[D^{\alpha-k}(U(t))\right]_{t=0}-$ $\left.u^{\alpha-1}(\partial U(t) / \partial t)\right|_{t=0}$. When we take the inverse Sumudu transform of (18) by using the inverse transform table in $[11,17]$, we get the solution of (16) by using STM as follows:

$$
\begin{aligned}
U(t)=S^{-1}[ & \frac{1}{1-u^{\alpha-2}-u^{\alpha-1}-u^{\alpha}} \\
& \left.\times\left[g(u)-u^{\alpha-1} U(0)-u^{\alpha-2} U(0)+c u^{\alpha}\right]\right] .
\end{aligned}
$$

\section{Applications of STM to Nonhomogeneous Fractional Ordinary Differential Equations}

In this section, we have applied STM to the nonhomogeneous fractional ordinary differential equations as follows.

Example 3. Firstly, we consider the nonhomogeneous fractional ordinary differential equation as follows [50]:

$$
\begin{aligned}
D^{\alpha}[U(t)]= & -U(t)+\frac{2}{\Gamma[3-\alpha]} t^{2-\alpha}-\frac{1}{\Gamma[2-\alpha]} t^{1-\alpha} \\
& +t^{2}-t, \quad t>0, \quad 0<\alpha \leq 1,
\end{aligned}
$$

With the initial condition being

$$
U(0)=0 .
$$

In order to solve (20) by using STM, when we take the Sumudu transform of both sides of (20), we get the Sumudu transform of (20) as follows:

$$
\begin{aligned}
& S\left[D^{\alpha} U(t)\right]+S[U(t)] \\
& =S\left[\frac{2}{\Gamma[3-\alpha]} t^{2-\alpha}-\frac{1}{\Gamma[2-\alpha]} t^{1-\alpha}+t^{2}-t\right], \\
& S\left[D^{\alpha} U(t)\right]+F(u)=S\left[\frac{2}{\Gamma[3-\alpha]} t^{2-\alpha}\right] \\
& -S\left[\frac{1}{\Gamma[2-\alpha]} t^{1-\alpha}\right]+S\left[t^{2}\right]-S[t], \\
& \frac{F(u)}{u^{\alpha}}-\left.\frac{D^{\alpha-1}[U(t)]}{u}\right|_{t=0}+F(u)=\frac{2}{\Gamma[3-\alpha]} S\left[t^{2-\alpha}\right] \\
& -\frac{1}{\Gamma[2-\alpha]} S\left[t^{1-\alpha}\right] \\
& +S\left[t^{2}\right]-S[t] \text {, } \\
& \frac{F(u)}{u^{\alpha}}+F(u)=\frac{2}{\Gamma[3-\alpha]} u^{2-\alpha} \Gamma[3-\alpha] \\
& -\frac{1}{\Gamma[2-\alpha]} u^{1-\alpha} \Gamma[2-\alpha]+2 u^{2}-u, \\
& \left(1+\frac{1}{u^{\alpha}}\right) F(u)=2 u^{2-\alpha}-u^{1-\alpha}+2 u^{2}-u \text {, } \\
& \left(1+u^{\alpha}\right) F(u)=2 u^{2}-u+2 u^{2+\alpha}-u^{1+\alpha}, \\
& \left(1+u^{\alpha}\right) F(u)=u(2 u-1)+u^{\alpha} u(2 u-1) \text {, } \\
& F(u)=(2 u-1) u, \\
& F(u)=2 u^{2}-u \text {. }
\end{aligned}
$$


When we take the inverse Sumudu transform of (22) by using the inverse transform table in [11], we get the analytical solution of (20) by STM as follows:

$$
U(t)=t^{2}-t
$$

Remark 4. If we take the corresponding values for some parameters into consideration, then the solution of (20) is in full agreement with the solution of (30) mentioned in [50]. To our knowledge, the analytical solution of FODEs that we find in this paper has been newly submitted to the literature.

Example 5. Secondly, we consider the nonhomogeneous fractional ordinary differential equation as follows [51]:

$$
D^{0.5} U(t)+U(t)=t^{2}+\frac{\Gamma[3]}{\Gamma[2.5]} t^{1.5}, \quad t>0,
$$

With the initial condition being

$$
U(0)=0 .
$$

In order to solve (24) by using STM, when we take the Sumudu transform of both sides of (24), we get the Sumudu transform of (24) as follows:

$$
\begin{gathered}
S\left[D^{0.5} U(t)\right]+S[U(t)]=S\left[t^{2}\right]+\frac{\Gamma[3]}{\Gamma[2.5]} S\left[t^{1.5}\right] \\
S\left[D^{0.5} U(t)\right]+S[U(t)]=S\left[t^{2}\right]+1.50451 S\left[t^{1.5}\right] \\
\frac{F(u)}{u^{0.5}}-\left.\frac{D^{\alpha-1}[U(t)]}{u}\right|_{t=0}+F(u) \\
=2 u^{2}+2 u^{1.5} \\
\Longrightarrow \frac{F(u)}{u^{0.5}+F(u)=2 u^{2}+2 u^{1.5}} \\
\left(\frac{1+u^{0.5}}{u^{0.5}}\right) F(u)=2 u^{2}+2 u^{1.5} \\
\Longrightarrow\left(1+u^{0.5}\right) F(u)=2 u^{2}+2 u^{1.5} \\
F(u)=\frac{2 u^{2.5}}{1+u^{0.5}}+\frac{2 u^{2}}{1+u^{0.5}}=\frac{2 u^{2}\left(1+u^{0.5}\right)}{1+u^{0.5}}=2 u^{2}
\end{gathered}
$$

When we take the inverse Sumudu transform of (26) by using the inverse transform table in [48], we get the analytical solution of (24) by using STM as follows:

$$
U(t)=t^{2} \text {. }
$$

Remark 6. The solution (27) obtained by using the Sumudu transform method for (24) has been checked by the Mathematica Program 7. To our knowledge, the analytical solution that we find in this paper has been newly submitted to the literature.

\section{Conclusion and Future Work}

Prior to this study, various approaches have been performed to obtain approximate solutions of some fractional differential equations $[50,51]$. In this paper, nonhomogeneous

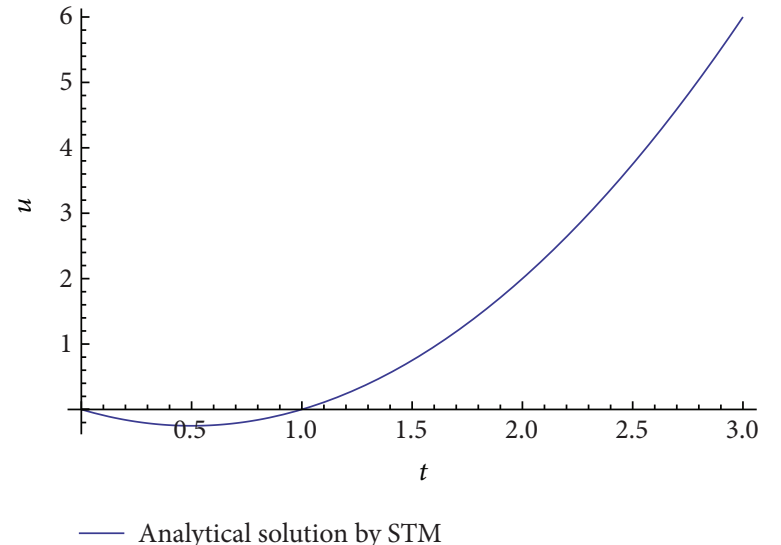

FIGURE 1: The 2D surfaces of the obtained solution by means of STM for (23) when $0<t<3$.

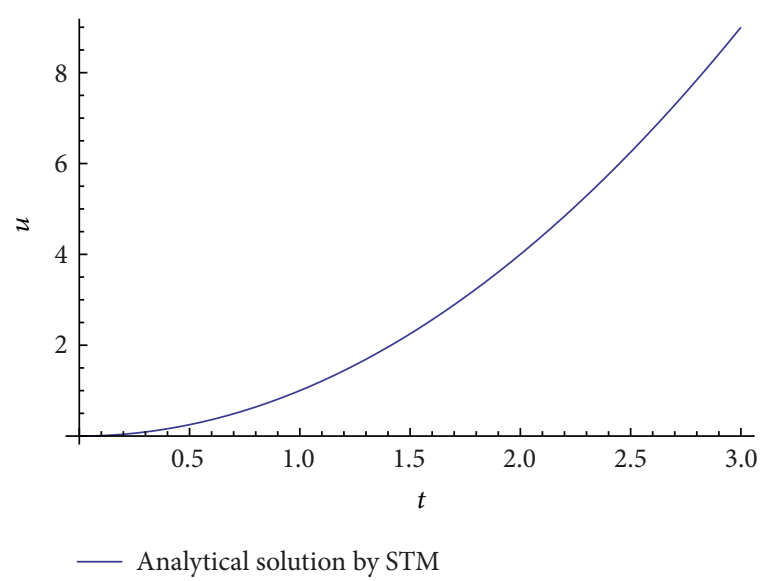

FIGURE 2: The 2D surfaces of the obtained solution by means of STM for (27) when $0<t<3$.

fractional ordinary differential equations have been solved by using the Sumudu transform after giving the related formulae for the fractional integrals, the derivatives, and the Sumudu transform of FODEs. The Sumudu technique can be used to solve many types such as initial-value problems and boundary-value problems in applied sciences, engineering fields, aerospace sciences, and mathematical physics. The Sumudu transform method has been used for The discrete fractional calculus in [43]. This technique has been investigated in terms of the double Sumudu transform in [44]. Consequently, this new approach has been implemented with success on interesting fractional ordinary differential equations. As such and pragmatically so, it enriches the library of integral transform approaches. Without a doubt, and based on our findings such as Figures 1 and 2, the STM technique remains direct, robust and valuable tool for solving same fractional differential equations.

\section{References}

[1] G. K. Watugala, "Sumudu transform: a new integral transform to solve differential equations and control engineering 
problems," International Journal of Mathematical Education in Science and Technology, vol. 24, no. 1, pp. 35-43, 1993.

[2] G. K. Watugala, "Sumudu transform-a new integral transform to solve differential equations and control engineering problems," Mathematical Engineering in Industry, vol. 6, no. 4, pp. 319-329, 1998.

[3] G. K. Watugala, "The Sumudu transform for functions of two variables," Mathematical Engineering in Industry, vol. 8, no. 4, pp. 293-302, 2002.

[4] S. Weerakoon, "Application of Sumudu transform to partial differential equations," International Journal of Mathematical Education in Science and Technology, vol. 25, no. 2, pp. 277-283, 1994.

[5] S. Weerakoon, "Complex inversion formula for Sumudu transform," International Journal of Mathematical Education in Science and Technology, vol. 29, no. 4, pp. 618-621, 1998.

[6] M. A. B. Deakin, "The "Sumudu transform" and the Laplace transform," International Journal of Mathematical Education in Science and Technology, vol. 28, p. 159, 1997.

[7] S. Weerakoon, "The "Sumudu transform" and the Laplace transform-reply," International Journal of Mathematical Education in Science and Technology, vol. 28, no. 1, p. 160, 1997.

[8] M. A. Asiru, "Sumudu transform and the solution of integral equations of convolution type," International Journal of Mathematical Education in Science and Technology, vol. 32, no. 6, pp. 906-910, 2001.

[9] M. A. Aşiru, "Further properties of the Sumudu transform and its applications," International Journal of Mathematical Education in Science and Technology, vol. 33, no. 3, pp. 441-449, 2002.

[10] F. B. M. Belgacem, A. A. Karaballi, and S. L. Kalla, "Analytical investigations of the Sumudu transform and applications to integral production equations," Mathematical Problems in Engineering, no. 3-4, pp. 103-118, 2003.

[11] F. B. M. Belgacem and A. Karaballi, "Sumudu transform fundamental properties investigations and applications," Journal of Applied Mathematics and Stochastic Analysis, Article ID 91083, 23 pages, 2006.

[12] F. B. M. Belgacem, "Introducing and analyzing deeper Sumudu properties Sumudu transform fundemantal properties investigations and applications," Nonlinear Studies Journal, vol. 1, no. 31, pp. 101-114, 2006.

[13] F. B. M. Belgacem, "Applications of the Sumudu transform to indefinite periodic parabolic problems," in Proceedings of the International Conference on Nonlinear Problems and Aerospace Applications (ICNPAA '06), chapter 6, pp. 51-60, 2006.

[14] M. G. M. Hussain and F. B. M. Belgacem, "Transient solutions of Maxwell's equations based on Sumudu transform," Progress in Electromagnetics Research, vol. 74, pp. 273-289, 2007.

[15] F. B. M. Belgacem, "Sumudu applications to Maxwell's equations," The Plan Index Enquiry and Retrieval System Online, vol. 5, pp. 355-360, 2009.

[16] F. B. M. Belgacem, "Sumudu transform applications to Bessel functions and equations," Applied Mathematical Sciences, vol. 4, no. 73-76, pp. 3665-3686, 2010.

[17] Q. D. Katatbeh and F. B. M. Belgacem, "Applications of the Sumudu transform to fractional differential equations," Nonlinear Studies, vol. 18, no. 1, pp. 99-112, 2011.

[18] S. Salinas, A. Jimenez, F. Arteaga, and J. Rodriguez, "Estudio analitico de la transformada de Sumudu y algunas aplicaciones a la teoria de control," Revista Ingeneria UC, vol. 11, no. 3, pp. 79-86, 2004 (Spanish).
[19] M. A. Rana, A. M. Siddiqui, Q. K. Ghori, and R. Qamar, "Application of He's homotopy perturbation method to Sumudu transform," International Journal of Nonlinear Sciences and Numerical Simulation, vol. 8, no. 2, pp. 185-190, 2007.

[20] A. Tamrabet and A. Kadem, "A combined Walsh function and Sumudu transform for solving the two-dimensional neutron transport equation," International Journal of Mathematical Analysis, vol. 1, no. 9-12, pp. 409-421, 2007.

[21] J. M. Tchuenche and N. S. Mbare, "An application of the double Sumudu transform," Applied Mathematical Sciences, vol. 1, no. 1-4, pp. 31-39, 2007.

[22] J. Zhang, "Sumudu transform based coefficients calculation," Nonlinear Studies, vol. 15, no. 4, pp. 355-372, 2008.

[23] V. B. L. Chaurasia, R. S. Dubey, and F. B. M. Belgacem, "Fractional radial diffusion equation analytical solution via Hankel and Sumudu transforms," International Journal of Mathematics in Engineering Science and Aerospace, vol. 3, no. 2, pp. 1-10, 2012.

[24] P. Goswami and F. B. M. Belgacem, "Fractional differential equation solutions through a Sumudu rational," Nonlinear Studies, vol. 19, no. 4, pp. 591-598, 2012.

[25] F. B. M. Belgacem, "Introducing and analysing deeper Sumudu properties," Nonlinear Studies, vol. 13, no. 1, pp. 23-41, 2006.

[26] F. B. M. Belgacem and R. Silambarasan, "Maxwell's equations solutions by means of the natural transform," International Journal of Mathematics in Engineering, Science And Aeorospace, vol. 3, no. 3, pp. 313-323, 2012.

[27] S. K. Alomari, "An estimate of Sumudu transforms for Boehmians," in Proceedings of the Conference on Mathematical problems in Engineering, Aerospace and Science, Vienna, Austria, 2012.

[28] H. Bulut, H. M. Baskonus, and S. Tuluce, "The solutions of partial differential equations with variable coefficients by sumudu transform method," AIP Proceeding, vol. 1493, p. 91, 2012.

[29] H. Z. Khan and W. A. Khan, "N-transform-properties and applications," NUST Journal of Engineering Sciences, vol. 1, no. 1, pp. 127-133, 2008.

[30] G. Adomian, "A review of the decomposition method and some recent results for nonlinear equations," Mathematical and Computer Modelling, vol. 13, no. 7, pp. 17-43, 1990.

[31] G. Adomian and R. Rach, "Equality of partial solutions in the decomposition method for linear or nonlinear partial differential equations," Computers \& Mathematics with Applications, vol. 19, no. 12, pp. 9-12, 1990.

[32] G. Adomian, Solving Frontier Problems of Physics: The Decomposition Method, vol. 60 of Fundamental Theories of Physics, Kluwer Academic Publishers, Boston, Mass, USA, 1994.

[33] G. Adomian, "A review of the decomposition method in applied mathematics," Journal of Mathematical Analysis and Applications, vol. 135, no. 2, pp. 501-544, 1988.

[34] Z.-G. Deng and G.-C. Wu, "Approximate solution of fractional differential equations with uncertainty," Romanian Journal of Physics, vol. 56, no. 7-8, pp. 868-872, 2011.

[35] M. A. Abdou and A. A. Soliman, "Variational iteration method for solving Burger's and coupled Burger's equations," Journal of Computational and Applied Mathematics, vol. 181, no. 2, pp. 245251, 2005.

[36] Z. M. Odibat and S. Momani, "Application of variational iteration method to nonlinear differential equations of fractional order," International Journal of Nonlinear Sciences and Numerical Simulation, vol. 7, no. 1, pp. 27-34, 2006. 
[37] J.-H. He and X.-H. Wu, "Variational iteration method: new development and applications," Computers \& Mathematics with Applications, vol. 54, no. 7-8, pp. 881-894, 2007.

[38] N. H. Sweilam, "Fourth order integro-differential equations using variational iteration method," Computers \& Mathematics with Applications, vol. 54, no. 7-8, pp. 1086-1091, 2007.

[39] S. Abbasbandy, "A new application of He's variational iteration method for quadratic Riccati differential equation by using Adomian's polynomials," Journal of Computational and Applied Mathematics, vol. 207, no. 1, pp. 59-63, 2007.

[40] A.-M. Wazwaz, "The variational iteration method for exact solutions of Laplace equation," Physics Letters A, vol. 363, no. 4, pp. 260-262, 2007.

[41] M. A. Asiru, "Application of the sumudu transform to discrete dynamical systems," International Journal of Mathematical Education, Science and Technology, vol. 34, no. 6, pp. 944-949, 2003.

[42] H. Bulut, H. M. Baskonus, and S. Tuluce, "Homotopy perturbation sumudu transform method for heat equations," Mathematics in Engineering, Science and Aerospace, vol. 4, no. 1, pp. 49-60, 2013.

[43] F. Jarad and K. Taş, "On Sumudu transform method in discrete fractional calculus," Abstract and Applied Analysis, vol. 2012, Article ID 270106, 16 pages, 2012.

[44] V. G. Gupta, B. Shrama, and A. Kiliçman, "A note on fractional Sumudu transform," Journal of Applied Mathematics, vol. 2010, Article ID 154189, 9 pages, 2010.

[45] R. C. Mittal and R. Nigam, "Solution of fractional integro-differential equations by adomian decomposition method," The International Journal of Applied Mathematics and Mechanics, vol. 4, no. 2, pp. 87-94, 2008.

[46] I. Podlubny, Fractional Differential Equations, vol. 198 of Mathematics in Science and Engineering, Academic Press, San Diego, Calif, USA, 1999.

[47] M. Caputo, "Linear model of dissipation whose Q is almost frequency independent-II," Geophysical Journal of the Royal Astronomical Society, vol. 13, no. 5, pp. 529-539, 1967.

[48] F. B. M. Belgacem and R. Silambarasan, "The Sumudu transform analysis by infinite series," in Proceedings of the AIP Proceeding, Vienna, Austria, 2012.

[49] P. Goswami and F. B. M. Belgacem, "Solving special fractional differential equations by the Sumudu transform," in Proceedings of the AIP Proceeding, Vienna, Austria, 2012.

[50] Z. M. Odibat and S. Momani, "An algorithm for the numerical solution of differential equations of fractional order," Journal of Applied Mathematics and Informatics, vol. 26, no. 1-2, pp. 15-127.

[51] N. J. Ford and A. C. Simpson, "The numerical solution of fractional differential equations: speed versus accuracy," Numerical Analysis Report no. 385, A Report in Association with Chester College, 2003. 


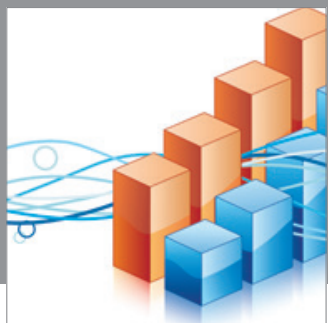

Advances in

Operations Research

mansans

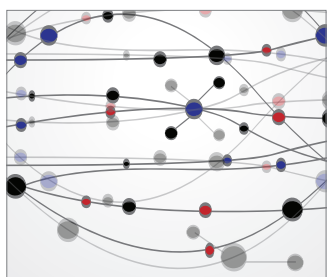

The Scientific World Journal
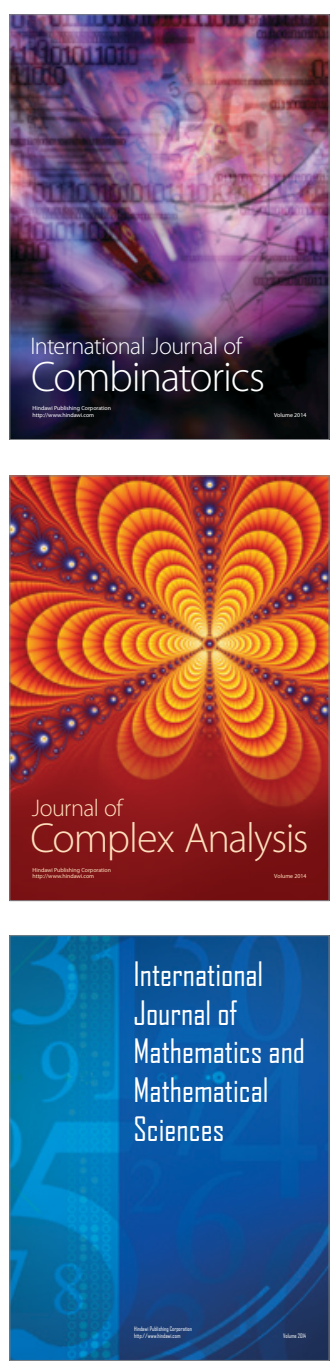
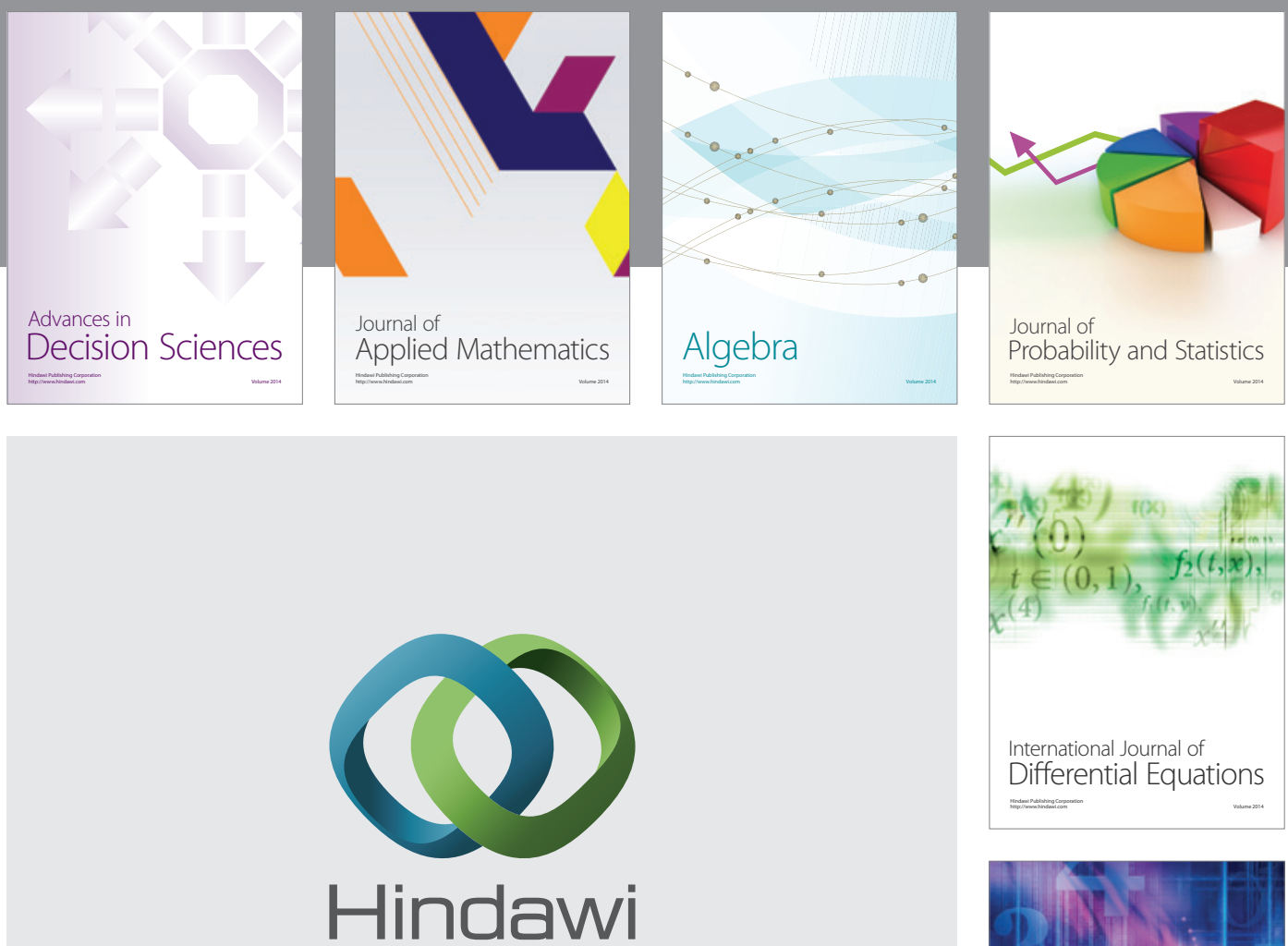

Submit your manuscripts at http://www.hindawi.com
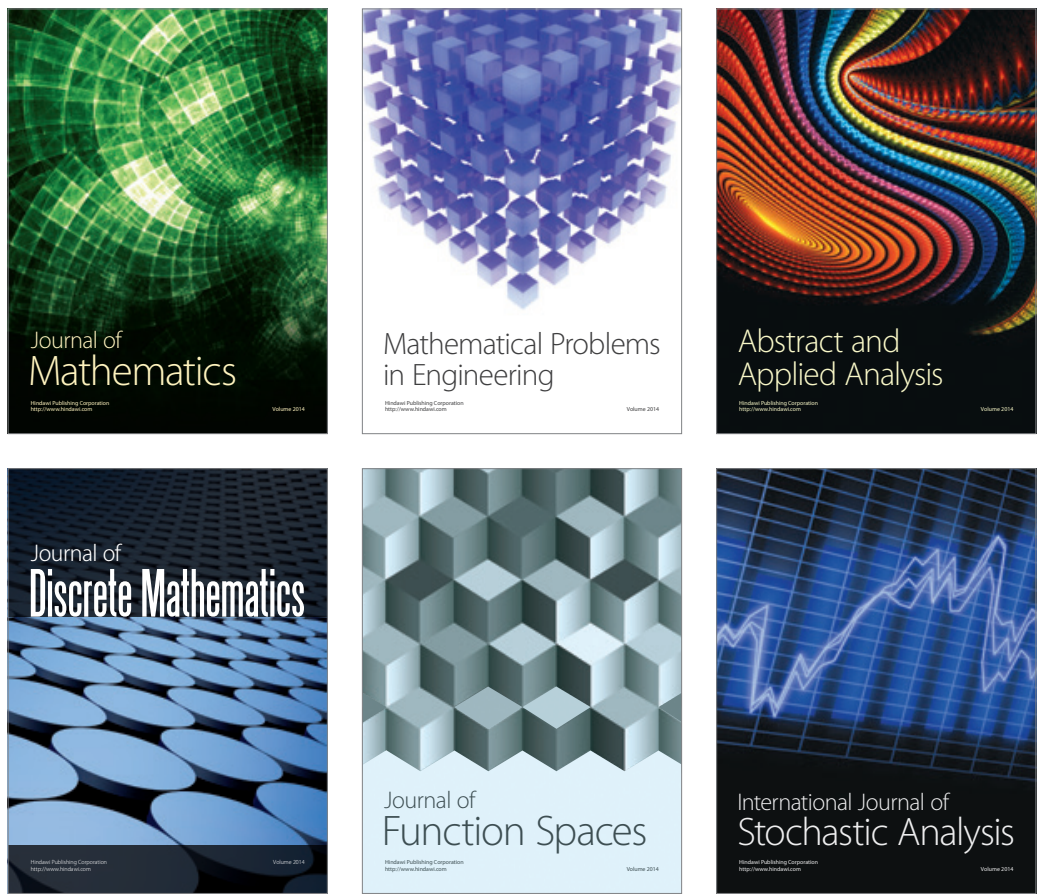

Journal of

Function Spaces

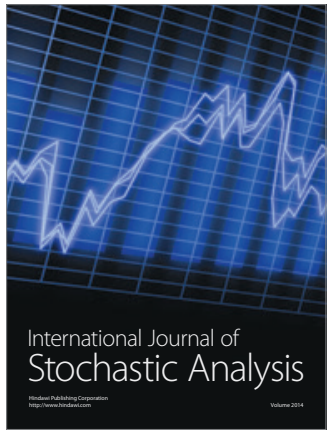

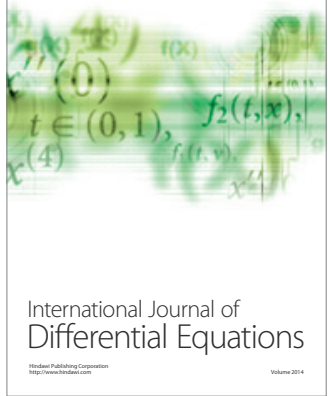
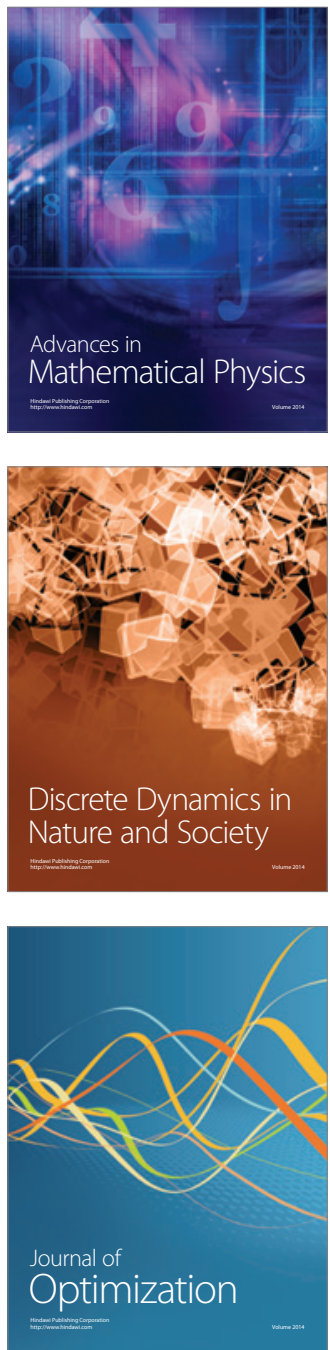